\title{
Intercultural Communication: Social attributes, Promoting Components, Impacts and Challenges
}

Rahul Kumar Satuna

\begin{abstract}
In the multifaceted and interconnected global civilization of today, each of us is shaped by many factors. Culture is one of the most influential factors that is profoundly inbuilt in our values and communication styles; and when it comes to share information among people with different surroundings, a lot of aspects come across. The sort of communication known as Intercultural communication primarily deals with understanding the patterns of interaction between cross cultures peoples/groups. The current paper discusses culture, intercultural communication along with four perspectives. The discussed four perspectives are (1) social attribute participating intercultural communication, (2) promoting components of intercultural communication, (3) impacts of intercultural communication, and (4) challenges with intercultural communication.
\end{abstract}

Keywords. Intercultural communication, Cross-culture communication. 


\section{Introduction}

Intercultural communication aims to share information across different cultures and social communities. It deals with processes and problems that obviously occur within an organization or social context made-up of persons belongs to different region, religion, society, education, and ethical backgrounds (Neuliep, J. W. 2017; House, J. 2014). Intercultural communication analyse the ideology of different cultured peoples and try to find out the way they perceive and act on some specific/common situations/things. In the era of global connectivity, it is highly required for individuals, business organizations, and governments to consider the intercultural communication as a critical feature in a successful communication process that can provide profits as well as ranking to their systems (Piller, I. 2017). "Preliminary, interaction in intercultural communication is possibly based on cultural stereotypes or generalizations" (Neuliep, J. W. 2017). According to Kealey (Kealey, D. J. 2015), “With today's global work scenario, there is increasing need to acquaint ourselves with the knowledge and art of dealing with people of different cultural backgrounds .... intercultural communication skills will facilitate resolving conflicts in a multicultural environment".

\section{Communication activity between different cultured individuals}

Intercultural communication could be illustrated as a scenario where two or more persons from different cultures exchange messages in a way that is influenced by their cultural perceptions, experiences, personal attributes, cognition and environment (by means of both verbal and nonverbal communication) as given in Figure 1. Finding common grounds in intercultural communication can be challenging and may lead to misunderstandings. To avoid this misunderstanding the different perspectives of intercultural communication should be understood in depth and practiced in day-to-day life. With this brief introduction of intercultural communication, the current paper is organized in seven sections. 'Culture' Section highlights the culture in intercultural communication. 'Social Attributes in Intercultural Communication' Section discusses social attributes participating in intercultural communication. Promoting components of intercultural communication are presented in Section 'Promoting Components'. Section 'Impact of Intercultural Communication' and Section 'Challenges with Intercultural Communication' elaborates the impacts and challenges of intercultural communication respectively.

\section{Culture}

"Culture is central to what we see, how we make sense of what we see, and how we express ourselves. Culture essentially is about how we communicate and it is reflected in both language and behaviour" (Lewis, I. 2017). A prominent sociologist, Geert Hofstede, defines culture as a kind of "collective software of the mind" as it involves a group's rules for collective behaviour, communication patterns and acceptable power play (Berg, M. 2015). Some comparable facts have been given (Minniie K. Juneja (2016) in a blog, where it is stated that about half of the people in this global village speak one of the following languages: 165 Mandarin, 83 Hindi / Urdu, 86 English, 64 Spanish, 58 Russian, 37 Arabic, the other half speak Bengali, Portuguese, Indonesian, Japanese, German, French and some 200 other languages. The language variety also defines various cultures in a nation. In an intercultural setting, these cultural factors assumed to have a considerable role; they inform how language is used since language is culturally mediated. Culture as the main driving force in intercultural communication affects perception, cognition and experience of the individual or community (Scott, C. P., \& Wildman, J. L. 2015). 


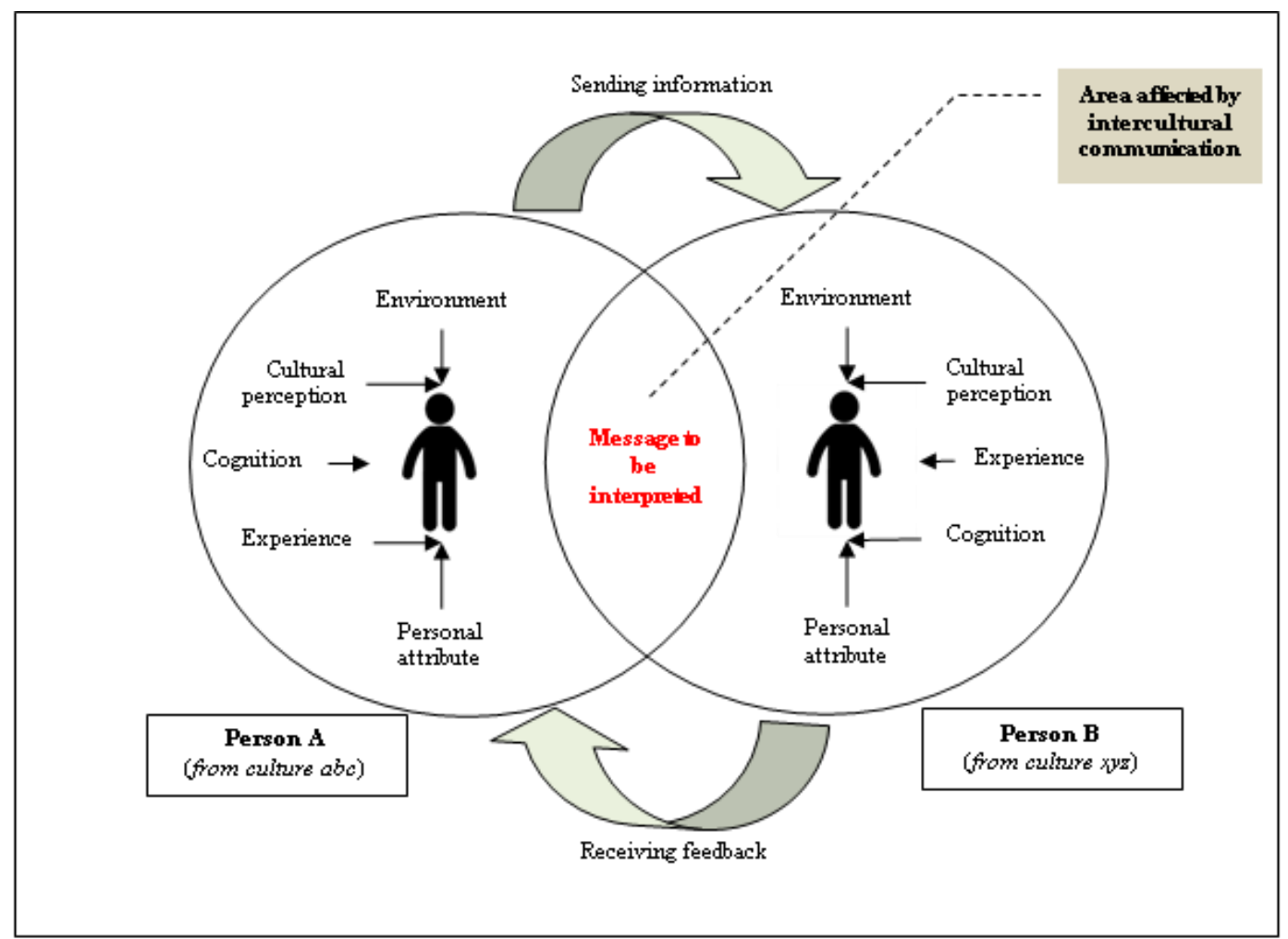

Figure 1. Communication activity flow between different cultured individuals

Social Attributes in Intercultural communication Social attributions plays an effusive role in intercultural communication, attributions are the drive force for cultural sharing, following traditions, learning's, customs and cultural believes following points are the base of social attributes.

a. Thought pattern: This is one of the most significant features that affect intercultural communication. The thought pattern of a society creates prejudice and enforces individuals to have generalized opinion about a particular person/group/community/nation (Ellis, A. W., \& Beattie, G. 2017).

b. Understanding different cultured languages and customs: To understand the core of the culture of other's communities change the intercultural communication conflicts and their resolutions. The openness of several features of cultures like language, customs, beliefs etc. helps better intercultural communication.

\section{Promoting Components}

As the globe is now driven by information, data, technology and its subsequent part for knowledge. below components are key elements for promoting.

a. Information and communication technologies (ICT): In today's scenario, main power which is making this earth as a global village is information and communication technology. The evolution of internet 
hikes intercultural communication most 100 times than year 1990 .

b. Personal interest

c. Organizational interest

d. National interest

\section{Impact of Intercultural communication}

Intercultural communication is working as a bond or viaduct between the nations and cultures. sharing of research, studies, business, services and a lots of things all over the globe are being carried through intercultural communication. Such as:

a. Social Science such as Anthropology, culture Studies, linguistics, psychology, and communication studies impact intercultural communication a lot.

b. Intercultural communication is base for International Businesses. In all over the world many cross-cultural service provider's works on research on Intercultural communication skills and develop ability practices to effectively work with people from other cultures.

c. Building Cultural Intelligence through coaching and training in Intercultural communication.

d. Cross-Culture Negotiations

e. Multi-Cultured Conflict Resolution

f. Customer Satisfaction

\section{Challenges with Intercultural communication}

With all the dynamics, intercultural communication is also facing challenges also below points are creating or working as barrier or drawbacks.

a. Trust between communicating parties

b. Intercultural awareness: It is conscious understanding of culturally based practices and frames of references that play a vital role in intercultural communication and further put this conception in action with a flexible and context specific mode in real time communication. c. Personal believes and experience and generalization with particular group.

\section{Conclusion}

Intercultural communication is mainly influenced by cultural believes and practices followed people. All of the discussed perspectives of intercultural communication in this paper can be summarized with this fact that our mind also has some sort of pre-built thoughts and initially we always behave or communicate as per those thought pattern. These thought patterns may create hurdles in effective communication process where some very sensitive issues being handled by person, group, organization or nation. The intercultural awareness with internet can play an important role and enhance efficacy of effective communication.

Rahul Kumar Satuna, Research scholar, Dev Sanskriti Vishwavidyalaya, Haridwar. Email rahul.satuna@dsvv.ac.in 


\section{References}

Berg, M. (2015). Collaboration in Intercultural Organizations according to the Cultural Dimension Models of Geert Hofstede.

Ellis, A. W., \& Beattie, G. (2017). The psychology of language and communication. Routledge.

House, J. (2014). Moving across languages and cultures in translation as intercultural communication. In Translational action and intercultural communication (pp. 14-46). Routledge.

Kealey, D. J. (2015). Some strengths and weaknesses of 25 years of Research on Intercultural Communication Competence: Personal Reflections. International Journal of Intercultural Relations, 48, 1416.

Lewis, I. (2017). Social and cultural anthropology in perspective: Their relevance in the modern world. Routledge.

Minniie K. Juneja (2016). Why Effective CrossCultural Communication Matters In Business. https://www.huffingtonpost.in/minniie-k-juneja/areyou-skilled-to-commun_b_9300246.html

Neuliep, J. W. (2017). Intercultural communication: A contextual approach. Sage Publications.

Piller, I. (2017). Intercultural communication: A critical introduction. Edinburgh University Press.

Scott, C. P., \& Wildman, J. L. (2015). Culture, communication, and conflict: A review of the global virtual team literature. In Leading global teams (pp. 13-32). Springer, New York, NY. 